4. He was a very respectable man, and not unlikely to have had money at the time in his possession.

The evidence on which the verdict was grounded was, that he had previously been in a depressed state of spirits, and that he had left a note on his table intimating his intention to destroy himself. These two circumstances appear to render the case very clear; but if it should eventually be shown that the man was poisoned, or murdered in some other way, such circumstances as these would be capable of a very ready explanation. The latter of the two might have been an ingenious contrivance of a murderer. At any rate, the jury did not, and without a medical inquiry could not, know that the man was not poisoned or strangled; and without having had the best opinion on such grave possibilities as these, they were tampering with the serious character of their office in asserting that he had "drowned himself." Of course juries, in these cases, act always in accordance with the Coroner's instructions.

I am acquainted with two other similarly imperfect inquests, which have been holden in the same village of Minster, since the passing of the Act for the Remuneration of Medical Witnesses. One was over the body of a woman who was fonnd hanging, and the other was held on the body of a child that was found burnt. The same provincial attorney presided at each of them, and singularly enough, before the existence of the above Act he invariably summoned medical witnesses to inquests in that neighbourhood. It appears that he now omits them because, like lawyers, they do not give their opinions " without being paid for them." I am, Sir, your very obedient servant,

James Freeman.

25, Charles-street, City-road, Jan. 15, 1839. ** Each of these cases, especially the last, affords a proper opportunity for remonstrating in the right quarter against the payment of a fee to the Coroner who so held the inquest. And with regard to the Medical Witnesses' Act, we again repeat, that prior to the existence of that statute, the Delasaux's and the beadles of the day were in the habit of summoning surgeons to attend inquests, in the most insulting and useless manner, with a certain know. ledge that remuneration would not follow the attendance of the witness. Medical men are now at least preserved from that species of annoyance and injustice. The neglect of duty by the Coroner forms the subject of another question, and that functionary, like all other officials, is amenable for his misconduct to the law, or liable to be mulct of his fees, on due representations being made in the proper quarter. Here is the remedy for unnecessary and imperfect inquests.

\section{SUGAR IN THE BLOOD OF} DIABETIC PATIENTS.

\section{To the Editor of TUE LANCET.}

SiR:-I cannot for a moment suppose that the blood of Sharper, my diabetic patient, contained any saccharine matter (vide LANCET, Aug. 4, 1838); at the same time I do not dispute the results in the cases adverted to by your correspondent " $D$," more especially since I have been informed, from the best authority, that Mr. M'Gregor of Glasgow is an accomplished chemist. (Vide Lancet, Aug. 11, 1838). I cannot find that the paper alluded to by your correspondent was ever published; nor was the name of $\mathrm{Mr}$. M'Gregor known to me before the notice of your correspondent. I am better pleased by the process adopted by $\mathbf{M r}$. M'Gregor than that of the Italian chemist, Ambrosini ; for in animal chemistry we ought, at all times, to adopt the most direct and simple processes, from obvious reasons. In looking, a few days ago, into the seventh volume of the French translation of Berzelius' " Chemistry," printed in the year 1833 , at page 80 , I found the following paragraph on the subject in question :-

" On a multiplié aussi les expériences chez les personnes affectes de diábetes, maladie durant laquelle lurine devient sucrée, pour retrouver le sucre diabetique dans le sang, mais jamais on n'en a découvert la moindre trace."

The experiments of Ambrosini and M'Gregor were, I believe, performed since the above was written by Berzelius; nevertheless, the paragraph is so decided that $I$ consider it my duty, with your permission, to lay it before the readers of THE LANCET.

Permit me, Sir, in conclusion to remark, that I would feel better pleased if accomplished correspondents (such as the gentleman who signs " $D$,") were to add their names to their communications. This is a practice which I follow in my efforts to throw light upon obscure points in my pro. fession. I remain, Sir, your obedient servant.

Sunderland, Jan. 17, 1839.

W. Reid Clanny.

\section{ROYAL I N S T I T UTION. Frlday, January 18th, 1839.}

ELECTRIC PROPERTIES OF THE RAIA TORPEDO, GYMNOTUS ELECTRICUS, AND SILURUS ELECTRICUS.

Mr. Faraday delivered this evening a lec. ture to a crowded audience on the electric powers of certain animals. He disclaimed, on the very threshhold of his discourse, any intention of reducing to a material standard the "principle of life," or divine scintillula, 